\title{
Fatores não-nutricionais e concentração de nitrogênio uréico no leite de vacas da raça Holandesa
}

\section{Paula Marques Meyer ${ }^{1,2}$, Paulo Fernando Machado ${ }^{3}$, Arlei Coldebella ${ }^{2,4}$, Laerte Dagher Cassoli ${ }^{2}$, Karyne Oliveira Coelho ${ }^{2}$, Paulo Henrique Mazza Rodrigues ${ }^{5}$}

\author{
* Parte da tese de doutorado da primeira autora desenvolvida na ESALQ/USP \\ ${ }^{1}$ Analista Agropecuário - IBGE, Rua Urussuí, n.93 - CEP: 04542-050 - São Paulo, SP. \\ 2 Pós-graduando - Depto. de Zootecnia - USP/ESALQ, C.P. 9 - CEP: 13418-900 - Piracicaba, SP. \\ ${ }^{3}$ Depto. de Zootecnia - USPIESALQ, C.P. 9 - CEP: 13418-900 - Piracicaba, SP. \\ ${ }^{4}$ Embrapa Suínos e Aves, C.P. 21 - CEP:89700-000 - Concórdia, SC. \\ ${ }^{5}$ Depto. de Nutrição e Produção Animal - USP/FMVZ, C.P. 23 - CEP: 13630-000 - Pirassununga, SP.
}

RESUMO - Estudou-se a relação de fatores não-nutricionais e a concentração de nitrogênio uréico no leite (NUL), com o objetivo de contribuir para sua avaliação como indicador da eficiência de utilização de dietas para vacas leiteiras. Foram utilizadas 7.006 observações provenientes de 855 vacas da raça Holandesa, incluindo dados coletados no dia da amostragem de leite referentes à produção de leite, ao peso vivo, ao número de dias em lactação (DEL) e ao número de lactações (NL). Nas amostras de leite coletadas mensalmente, foram determinadas as concentrações de gordura, proteína, lactose, sólidos totais (ST), a contagem de células somáticas (CCS) e NUL. Foram também calculadas as variáveis produção de leite corrigida para 4\% de gordura (LCG4\%) e relação gordura/proteína. Efetuaram-se análises de regressão linear simples utilizando os dados coletados como variáveis independentes e as concentrações de NUL como variável dependente. A concentração média de NUL foi 13,3 mg/dL e a produção de leite média foi $35,8 \mathrm{~kg} /$ dia. Houve associação negativa entre as concentrações de gordura, proteína, lactose e sólidos totais e a CCS (transformada em logaritmo natural) e associação positiva entre as produções de leite, lactose e sólidos totais (kg) e a concentração de NUL. A produção de leite corrigida para $4 \%$ de gordura, DEL, NL e a produção de gordura e proteína se correlacionaram com a concentração de NUL, porém, não houve ajuste da equação linear. Entretanto, o peso corporal e a relação gordura/proteína não se correlacionaram com as concentrações de NUL. Entre os fatores não-nutricionais, a produção de leite e a concentração de proteína do leite foram os fatores que mais se correlacionaram com as concentrações de NUL.

Palavras-chave: NUL, produção de leite, proteína do leite, uréia no leite, vaca leiteira

\section{Effects of non-dietary factors on milk urea nitrogen in lactating Holstein cows}

\begin{abstract}
The objective of this study was to evaluate the association of non-dietary factors on the concentration of milk urea nitrogen (MUN), as an indicator of efficiency of nutrient utilization by lactating dairy cows. A dataset containing 7,006 observations from 855 lactating Holstein cows were used. Milk yield, body weight, days in milk and number of lactation were collected on the milk sampling days. Monthly samples of milk were collected to determine contents of milk fat, protein, lactose, total solids, MUN and somatic cells count (SCC). Yield of milk components (fat, protein, lactose and total solids) as well as $4 \%$ fat-corrected milk (FCM) were also used in the study. Regression analyses of MUN, as the dependent variable, on FCM, SCC and content and yield of milk components were done to analyze the data. Mean MUN and milk yield averaged $13.3 \mathrm{mg} / \mathrm{dL}$ and $35.8 \mathrm{~kg} / \mathrm{day}$, respectively. Milk contents of fat, protein, lactose and total solids as well as SCC (natural logarithm transformed) were negatively associated with MUN while the opposite was observed for yields of milk lactose and total solids and milk production. Yields of milk fat and milk protein $(\mathrm{kg}), \mathrm{FCM}$, days in milk and number of lactation all were correlated with MUN, however there was lack of fit for the linear equation. No significant correlations between MUN and body weight and MUN and fat:protein ratio were observed. Among the non-dietary factors, milk yield and milk protein concentration correlated most with MUN.
\end{abstract}

Key Words: dairy cow, milk yield, MUN, milk protein

\section{Introdução}

A concentração de nitrogênio uréico no leite (NUL) apresenta alta correlação com a concentração de nitrogênio uréico no plasma ou no sangue $(\mathrm{r}=0,88$; Roseleretal., 1993), pois a uréia é uma pequena molécula neutra (sem carga) que se difunde facilmente pelas membranas (Jonker et al., 1998). Desse modo, a concentração de NUL tem sido utilizada como indicador para o monitoramento da nutrição protéica (Jonker et al., 1999; Kohn, 2000), principalmente pela adequação da relação entre proteína e energia da dieta de vacas em lactação (Oltner \& Wiktorsson, 1983; Oltner et al., 1985; Broderick \& Clayton, 1997). 
Para determinação da concentração de NUL, as amostras são coletadas de forma não-invasiva e direta, por meio da amostragem de leite durante as ordenhas, representando, portanto, um indicador simples, rápido e de baixo custo para avaliação do status nutricional de vacas em lactação (Roseler et al., 1993; Butler et al., 1995), constituindo uma ferramenta auxiliar no ajuste da dieta de vacas em lactação.

Contudo, para interpretar as concentrações de NUL corretamente, é importante considerar outros fatores que influenciaram os diferentes resultados apresentados na literatura. Além de fatores relacionados à dieta, a produção de leite (Oltner et al., 1985; Carlsson et al., 1995), a idade da vaca (Carlsson et al., 1995), o estádio da lactação (Carlsson et al., 1995), o peso vivo (Oltner et al., 1985; Jonker et al., 1998) e as concentrações de proteína (Jonker et al., 1999) e gordura do leite (Jonker et al., 1998) também podem alterar a concentração de NUL. Variações diurnas da concentração de NUL foram relatadas por alguns pesquisadores que relacionaram o tempo entre a alimentação e a coleta da amostra (Gustafsson \& Palmquist, 1993; Roseler etal., 1993; Carlsson \& Bergström, 1994). Variações sazonais também foram registradas por Carlsson \& Pehrson (1993), os quais notaram que a concentração de NUL no período em que as vacas estavam sob pastejo foi maior que no período de confinamento.

Entretanto, a associação entre NUL e outras variáveis deveria ser determinada nas condições de campo, usando procedimentos de rebanhos comerciais, visando validar o indicador como método prático. Este estudo foi realizado com o objetivo de validar a relação entre fatores nãonutricionais e a concentração de NUL em vacas da raça Holandesa em condições de rebanho comercial.

\section{Material e Métodos}

Foram utilizadas 7.006 observações coletadas no período de setembro de 2000 a janeiro de 2002 , referentes a 855 vacas da raça Holandesa, pertencentes ao rebanho da Fazenda Colorado, situada no município de Araras - SP.

Os animais foram confinados em estábulo do tipofreestall, dotado de ventiladores e aspersores, acionados automaticamente quando a temperatura ambiente ultrapassava $23^{\circ} \mathrm{C}$. Após o parto, os animais foram ordenhados três vezes ao dia, em sala de ordenha do tipo "espinha de peixe", $2 \times 12$, linha baixa, com sistema de coleta de dados AFIMILK ${ }^{\circledR}$ - SAE AFIKIM, em que cada animal é identificado e tem sua produção de leite registrada a cada ordenha, para obtenção da produção diária. Os dados diários de produção de leite foram automaticamente lançados em software de controle leiteiro para avaliação gerencial do rebanho.
Os animais foram alimentados sete vezes ao dia (primeiro fornecimento às $5 \mathrm{~h}$ e o último, às $21 \mathrm{~h}$ ) com ração total única, composta, com base na MS, de 42,0\% de silagem de milho, 6,5\% de pré-secado de Cynodon dactylon, 14,0\% de farelo de soja, $11,0 \%$ de gérmen de milho, $15,4 \%$ de silagem de grão úmido de milho, $2,2 \%$ de farelo de glúten de milho, $6,6 \%$ de polpa cítrica e $2,2 \%$ de mistura mineral. O volumoso foi fornecido em proporção correspondente a $48 \%$ da dieta, em MS. Para alimentação do rebanho, foi utilizado vagão de mistura total (TMR) de $10 \mathrm{~m}^{3}$, com desensilador e balança eletrônica. A composição da dieta e o consumo médio de matéria seca (CMS) do rebanho (kg/ animal/dia) são apresentados na Tabela 1.

Utilizaram-se vacas com cinco lactações ou menos, com até 305 dias em lactação e concentração de NUL inferior a $25 \mathrm{mg} / \mathrm{dL}$. Dados da produção de leite ( $\mathrm{kg} / \mathrm{dia})$, peso vivo $(\mathrm{kg})$, dias em lactação (DEL) e número de lactações (NL) foram coletados no dia da amostragem de leite. As amostras de leite foram coletadas mensalmente sempre na ordenha da manhã e transferidas diretamente do medidor para frascos de coleta $(60 \mathrm{~mL})$ contendo duas pastilhas de bronopol (largo espectro) como conservante. Em seguida, foram homogeneizadas por, no mínimo, 15 segundos e encaminhadas à Clínica do Leite do Departamento de Zootecnia da Escola Superior de Agricultura "Luiz de Queiroz"/ USP, para determinação das concentrações de gordura, proteína, lactose, sólidos totais (ST) (\%) e NUL (mg/dL) e da contagem de células somáticas (CCS) $\left(\times 10^{3}\right.$ células $\left./ \mathrm{mL}\right)$.

As concentrações de gordura, proteína, lactose e sólidos totais foram determinadas por leitura de absorção infravermelha utilizando-se o equipamento Bentley $2000^{\circledR}$ e a CCS foi realizada pelo método de citometria fluxométrica utilizando-se equipamento Somacount $300^{\circledR}$. As concentrações de NUL foram estimadas utilizando-se o equipamento ChemSpeck $150^{\circledR}$, por método enzimático e espectrofotométrico de trans-reflectância.

A produção de leite corrigida para $4 \%$ de gordura (LCG4\%) foi calculada pela equação: $(0,4 * \mathrm{~kg}$ de leite produzido $)+\left(15^{*} \mathrm{~kg}\right.$ de gordura produzida), de acordo com NRC (1989). A produção dos componentes do leite (gordura, proteína, lactose e sólidos totais) em $\mathrm{kg}$ foi estimada pela multiplicação da produção de leite pela respectiva concentração do componente do leite, dividindo-se esse número por 100. A relação gordura/proteína (rel. G/P) foi obtida da divisão da concentração de gordura pela de proteína do leite.

Análises de regressão linear simples foram realizadas pelo PROC REG do SAS (1999) utilizando-se os dados coletados como variáveis independentes e as concentrações de NUL como variável dependente. Entretanto, ao 
Tabela 1 - Composição das dietas e consumo médio de matéria seca do rebanho Table 1 - Composition of diets and mean dry matter intake of the herd

Composição da dieta

Diet composition

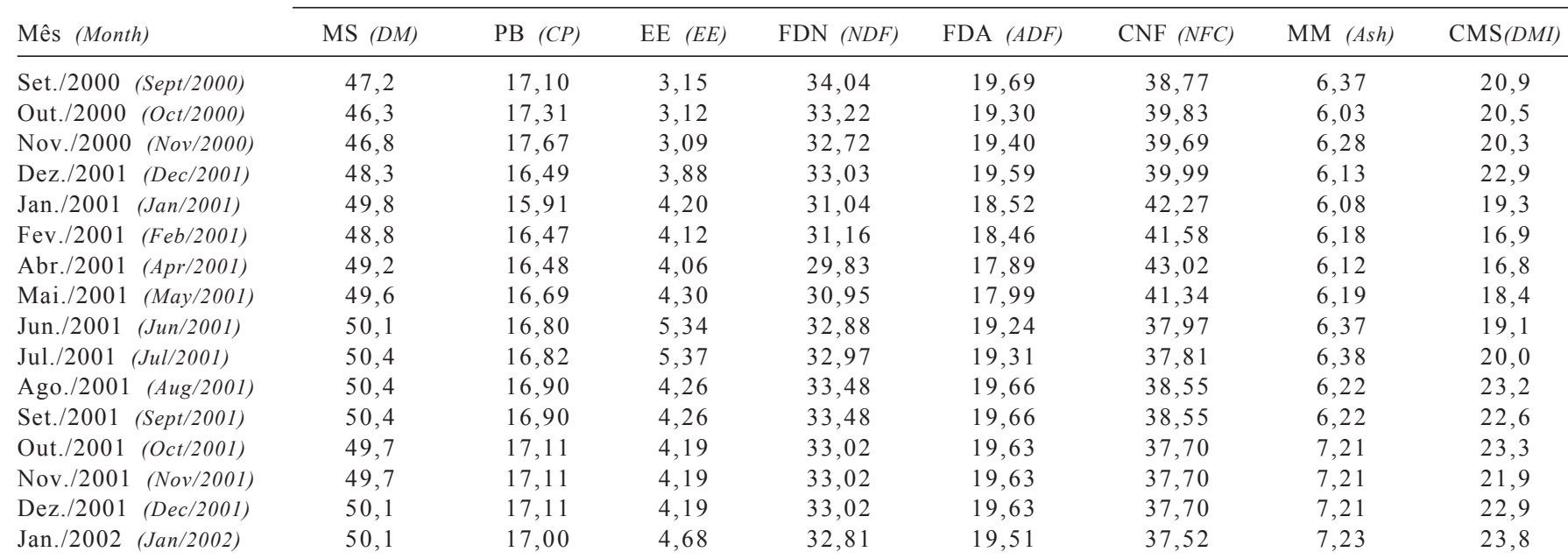

MS = matéria seca (\%); PB = proteína bruta (\% MS); EE = extrato etéreo (\% MS); FDN = fibra em detergente neutro (\% MS); FDA = fibra em detergente ácido (\% MS); CNF = carboidratos não-fibrosos (\% MS); MM = matéria mineral (\% MS); CMS = consumo médio de matéria seca do rebanho (kg/animal/dia). $D M=$ dry matter (\%); $C P=$ crude protein (\% DM); $E E=$ ether extract (\% DM); NDF = neutral detergent fiber (\% DM); ADF = acid detergent fiber $(\%$ DM); NFC = non-fiber carbohydrates (\% $D M) ;$ ash (\% DM); DMI = dry matter intake of the herd ( $\mathrm{kg} /$ animal/day).

considerar a existência de repetições das variáveis estudadas, os modelos só poderiam explicar os valores médios de cada variável. Portanto, os coeficientes de determinação $\left(\mathrm{r}^{2}\right)$ foram recalculados para exprimir melhor os efeitos das variáveis sobre as concentrações de NUL. Para esses cálculos, foram realizadas análises de regressão linear simples, considerando as variáveis independentes como variáveis classificatórias, ou seja, cada valor se torna uma classe. A partir daí, a soma de quadrados do modelo de regressão foi dividida pela soma de quadrados do modelo analisado com a variável classificatória, para obtenção do coeficiente de determinação $\left(\mathrm{r}^{2}\right)$. O teste de falta de ajuste da equação linear foi realizado de acordo com Neter et al. (1996) e Souza (1998).

Utilizou-se ainda a correlação entre a produção de leite e as outras variáveis estudadas, calculando-se os coeficientes de correlação linear simples, por meio do PROC CORR do SAS (1999).

A contagem de células somáticas $\left(\mathrm{x} 10^{3}\right.$ células $\left./ \mathrm{mL}\right)$ foi transformada em logaritmo natural (LCCS) pela equação $\ln (\mathrm{CCS}+1)$, pois não possui distribuição normal (Godden et al., 2001b).

\section{Resultados e Discussão}

A média geral da concentração de NUL foi $13,30 \mathrm{mg} / \mathrm{dL}$ (amplitude de 2,22 a 24,92). Os animais apresentaram produção média diária de leite de $35,81 \mathrm{~kg}$, com média de 2,19 lactações e 153,70 dias em lactação, pesando, em média, $646,30 \mathrm{~kg}$, conforme demonstrado na Tabela 2.
Tabela 2 - Análise descritiva das variáveis estudadas Table 2 - Descriptive analysis of the studied variables

\begin{tabular}{|c|c|c|c|}
\hline $\begin{array}{l}\text { Variável } \\
\text { Variable }\end{array}$ & $\mathrm{n}^{1}$ & $\begin{array}{l}\text { Média } \\
\text { Mean }\end{array}$ & $\begin{array}{l}\mathrm{EPM}^{2} \\
S E M^{2}\end{array}$ \\
\hline $\begin{array}{l}\text { Nitrogênio uréico } \\
\text { no leite }(\mathrm{mg} / \mathrm{dL})\end{array}$ & 7.006 & 13,30 & 0,0410 \\
\hline Milk urea nitrogen $(\mathrm{mg} / \mathrm{dL})$ & & & \\
\hline $\begin{array}{l}\text { Produção de leite (kg/dia) } \\
\text { Milk yield ( } k g / \text { day) }\end{array}$ & 7.000 & 35,81 & 0,1041 \\
\hline $\begin{array}{l}\text { Leite corrigido para } \\
4 \% \text { de gordura }(\mathrm{kg} / \mathrm{dia})\end{array}$ & 7.000 & 31,29 & 0,0962 \\
\hline $\begin{array}{l}4 \% \text { fat corrected milk }(\mathrm{kg} / \text { day }) \\
\text { Peso corporal }(\mathrm{kg})\end{array}$ & 3.868 & 646,30 & 1,4595 \\
\hline Body weight ( $\mathrm{kg}$ ) & & & \\
\hline $\begin{array}{l}\text { Número de lactações } \\
\text { Number of lactations }\end{array}$ & 7.006 & 2,19 & 0,0148 \\
\hline $\begin{array}{l}\text { Dias em lactação } \\
\text { Days in milk }\end{array}$ & 7.006 & 153,70 & 0,9755 \\
\hline Gordura (Fat) (\%) & 7.006 & 3,20 & 0,0098 \\
\hline Proteína $(\%)$ & 7.006 & 3,07 & 0,0039 \\
\hline Protein (\%) & & & \\
\hline Lactose $(\%)$ & 7.006 & 4,74 & 0,0038 \\
\hline Sólidos totais $(\%)$ & 7.006 & 11,86 & 0,0122 \\
\hline Total solids (\%) & & & \\
\hline $\begin{array}{l}\text { Produção de gordura (kg/dia) } \\
\text { Fat yield (kg/day) }\end{array}$ & 7.000 & 1,13 & 0,0043 \\
\hline $\begin{array}{l}\text { Produção de proteína }(\mathrm{kg} / \mathrm{dia}) \\
\text { Protein yield ( } \mathrm{kg} / \text { day) }\end{array}$ & 7.000 & 1,09 & 0,0029 \\
\hline $\begin{array}{l}\text { Produção de lactose ( } \mathrm{kg} / \text { dia) } \\
\text { Lactose yield ( } \mathrm{kg} / \text { day) }\end{array}$ & 7.000 & 1,70 & 0,0051 \\
\hline $\begin{array}{l}\text { Produção de sólidos } \\
\text { totais }(\mathrm{kg} / \mathrm{dia})\end{array}$ & 7.000 & 4,22 & 0,0117 \\
\hline Total solids yield ( $\mathrm{kg} /$ day) & & & \\
\hline $\operatorname{LCCS}(\operatorname{LSCC})^{3}$ & 7.006 & 4,25 & 0,0179 \\
\hline Relação gordura/proteína & 7.006 & 1,05 & 0,0033 \\
\hline
\end{tabular}

${ }^{1}$ Número amostral; ${ }^{2}$ erro-padrão da média; ${ }^{3}$ logaritmo natural (contagem de células somáticas +1 )

${ }^{1}$ Number of samples, ${ }^{2}$ standard error of mean; ${ }^{3}$ natural logarithm (somatic cells count +1 ). 
Tabela 3 - Equações, coeficientes de determinação da análise de regressão linear simples e probabilidades, utilizando-se as concentrações de nitrogênio uréico no leite como variável dependente

Table 3 - Regression equations, coefficients of determination, and probabilities using milk urea nitrogen as dependent variable

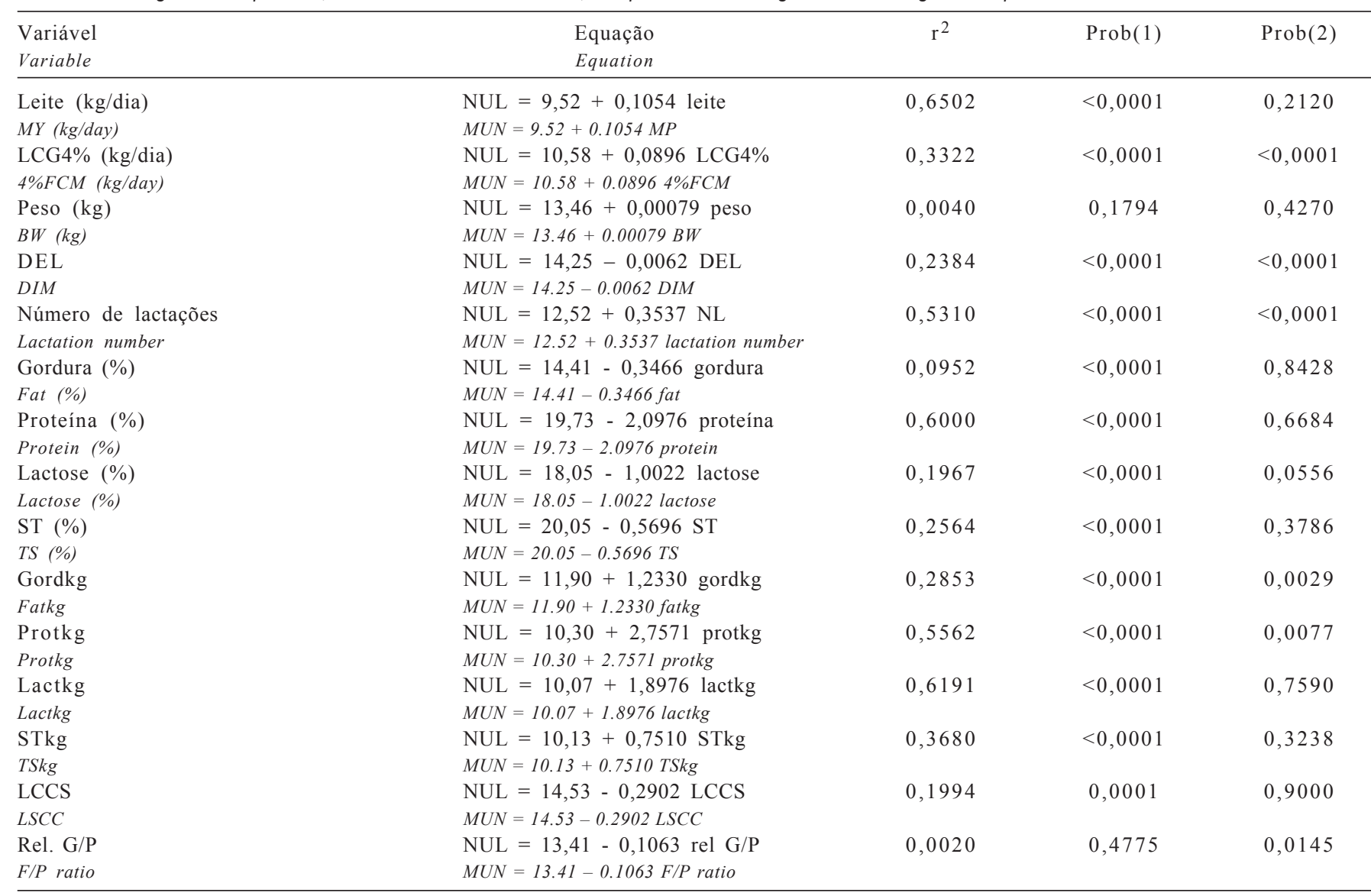

$r^{2}$ = coeficiente de determinação; Prob (1) = probabilidade estatística de o coeficiente angular da reta ("slope") diferir de zero; Prob(2) = probabilidade estatística da falta de ajuste da equação linear; Leite = produção de leite; LCG4\% = produção de leite corrigida para $4 \%$ de gordura; DEL = dias em lactação; Gordkg = produção de gordura em kg; Protkg = produção de proteína em kg; Lactkg = produção de lactose em kg; STkg = produção de sólidos totais em kg; $\mathrm{LCCS}=$ In (contagem de células somáticas +1 ); Rel. G/P = relação gordura/proteína; NUL= nitrogênio uréico no leite (mg/dL).

$r^{2}=$ coefficient of determination; Prob(1) = statistical probability of the slope to differ from zero; Prob(2) = statistical probability of lack of fit of the linear equation; $M Y=$ milk yield; $4 \%$ FCM = $4 \%$ fat corrected milk; DIM = days in milk; Fatkg = fat yield in kg; Protkg= protein yield in $\mathrm{kg} ;$ Lactkg = lactose yield in $\mathrm{kg} ;$ TSkg = total solids yield in $\mathrm{kg} ;$ LSCC = In (somatic cells count +1), $F / P$ ratio $=$ fat $/$ protein ratio; $M U N=$ milk urea nitrogen $(\mathrm{mg} / \mathrm{dL})$.

Os efeitos individuais das variáveis estudadas sobre as concentrações de NUL, analisados por regressão linear simples, são apresentados na Tabela 3.

Pelo coeficiente de determinação $\left(r^{2}=0,6502\right)$, constatou-se que a produção média diária de leite foi a variável que mais influenciou a concentração de NUL (Tabela 3). Não foi observada falta de ajuste da equação linear para essa variável ( $\mathrm{P}=0,2120)$, ou seja, a equação explicou bem o efeito da produção de leite sobre NUL. Para cada $1 \mathrm{~kg}$ a mais na produção diária de leite, houve aumento de $0,1054 \mathrm{mg} / \mathrm{dL}$ na concentração de NUL ( $\mathrm{P}<0,0001)$. Entretanto, Arunvipas et al. (2002) observaram, a cada aumento de $1 \mathrm{~L}$ na produção de leite/vaca/dia, acréscimo de $0,05 \mathrm{mg} / \mathrm{dL}$ na concentração de NUL, com média de NUL de 11,17 mg/dL.

Oltner et al. (1985) também notaram correlação positiva entre produção de leite e concentração de uréia no leite. Kaufmann (1982) encontrou relação similar, a qual foi atribuída aos aumentos no conteúdo de proteína na dieta e na produção de leite, e não somente ao efeito da produção de leite. A associação entre uréia no leite e produção verificada por Godden et al. (2001a) foi positiva, mas não-linear.

Alguns autores (Oltner \& Wiktorsson, 1983; Oltner et al., 1985; Broderick \& Clayton, 1997) sugeriram que o efeito da produção de leite sobre as concentrações de NUL é causado pela elevada correlação entre a produção de leite e a relação proteína/energia na dieta. Chalupa (1984) e Oldham (1984) consideraram essa associação positiva resultado do maior teor de proteína dietética consumida. A proteína suplementar pode aumentar a produção de leite, por fornecer mais aminoácidos para a síntese de proteína do leite, aumentar a energia disponível a partir da deaminação dos aminoácidos ou alterar a eficiência de utilização dos nutrientes absorvidos (Chalupa, 1984).

MacLeod et al. (1984) reportaram que a elevação nos teores de proteína na dieta aumentou o consumo de MS, resultando, indiretamente, em maior consumo de energia. 
Contudo, há um padrão de aumentos decrescentes em que as respostas na produção de leite à proteína adicional, eventualmente, se tornam cada vez menores (Hogan, 1975; Edwards et al., 1980; Kung Jr. \& Huber, 1983). Godden et al. (2001a) concluíram que a variabilidade na quantidade e qualidade dos alimentos pode explicar as diferenças na associação entre uréia no leite e produção de leite.

Neste estudo, todas as vacas consumiram a mesma dieta e, portanto, não houve variações quanto ao número de lactações, aos dias em lactação ou à produção de leite. Uma possível explicação para o aumento nas concentrações de NUL, em relação ao aumento na produção de leite pode ser o fato de que o nutriente limitante para vacas de alta produção é a energia. Assim, para obter a ingestão de energia necessária, o animal aumentaria o consumo de MS, ingerindo proteína em excesso, em relação à energia.

Os resultados de NUL deste estudo estão de acordo com os estimados por Jonker et al. (1998), os quais relataram que rebanhos produzindo entre 8.000 e $12.000 \mathrm{~kg}$ de leite/ vaca/lactação apresentariam concentração de NUL de 10 e $16 \mathrm{mg} / \mathrm{dL}$, respectivamente. Esses autores sugerem que o potencial de produção de leite do rebanho seja considerado nos padrões de referência das concentrações de NUL, pois é o principal fator a influenciar NUL.

Trevaskis \& Fulkerson (1999) observaram que a produção de leite de vacas em pastejo foi negativamente relacionada à concentração de uréia no leite, possivelmente em decorrência de um efeito de diluição. Outra possível explicação para a relação negativa entre uréia no leite e produção seria que a taxa energética, associada à conversão de quantidades excessivas de amônia em uréia, pode contribuir para diminuir a energia disponível para produção de leite (Nelson, 1995). Por outro lado, Gustafsson \& Carlsson (1993) e Eicher et al. (1999) não encontraram associações entre uréia no leite e produção de leite. A produção de leite corrigida para $4 \%$ de gordura (LCG4\% em $\mathrm{kg} /$ dia) apresentou coeficiente de determinação $\left(\mathrm{r}^{2}\right)$ de 0,3322 , metade daquele referente à produção de leite sem correção, o que explica 33\% da variação de NUL. Apesar da observação de que o coeficiente angular da reta difere de zero $(\mathrm{P}<0,0001)$, nota-se falta de ajuste da equação linear para essa variável $(\mathrm{P}<0,0001)$ (Tabela 3$)$. Godden et al. (2001a) também registraram associação positiva, mas nãolinear, entre uréia no leite e produção de leite corrigida para $3,5 \%$ de gordura e também para a produção de leite corrigida para energia $(3,5 \%$ de gordura e $3,2 \%$ de proteína). Os autores propõem que, embora a relação entre uréia no leite e essas três medidas de produção de leite pareça similar, o ajuste do modelo foi melhor quando a produção foi corrigida para energia. Apesar de a falta de ajuste da equação linear não ter sido significativa $(\mathrm{P}=0,4270)$ (Tabela 3$)$, o peso corporal não influenciou as concentrações de NUL $(\mathrm{P}=0,1794)$ e o coeficiente de determinação foi baixo $\left(\mathrm{r}^{2}=0,0040\right)$, indicando que essa variável pouco explica a variação nas concentrações de NUL.

Esse resultado corrobora os achados de Jonker et al. (1999), demonstrando que menos de 3\% da variação de NUL, em seu modelo, foi atribuída à variação no peso corporal. Esses autores ressaltaram que a variação nas medições de peso corporal causada pelo enchimento gastrintestinal, o volume de leite na glândula mamária e os métodos de medições adicionaram tanta variação nas predições de seu modelo original (Jonker et al., 1998) que sua inclusão não se justificou nesse modelo. Por outro lado, Oltner et al. (1985) e Jonker et al. (1998) relataram que o peso corporal apresentou correlação negativa com as concentrações de NUL em vacas leiteiras em lactação.

Para as variáveis dias em lactação (DEL), número de lactações (NL) e relação gordura/proteína (rel. G/P), a equação linear não foi adequada para explicar suas associações com NUL, pois apresentou falta de ajuste $(\mathrm{P}<0,02)$, como demonstrado na Tabela 3. Entretanto, observou-se efeito ( $\mathrm{P}<0,0001)$ dessas variáveis sobre NUL, excetuando-se a relação gordura/proteína $(\mathrm{P}=0,4775)$. $\mathrm{O}$ coeficiente de determinação, no entanto, foi baixo para a relação gordura/ proteína $\left(\mathrm{r}^{2}=0,0020\right)$, enquanto, para DEL e NL, foi mais alto, com valores de aproximadamente 0,2384 e 0,5310, respectivamente.

Há controvérsias na literatura sobre a variação das concentrações de NUL entre os estádios de lactação. Alguns pesquisadores (Bruckental et al., 1980; Emanuelson et al., 1993; Carlsson et al., 1995) reportaram que os valores médios de uréia no leite durante o primeiro mês de lactação foram mais baixos que nos meses subseqüentes. Godden et al. (2001a) notaram associação positiva, mas não-linear, entre uréia no leite e DEL e observaram que as concentrações de NUL foram mais baixas nos primeiros 60 dias, aumentando entre 60 e 150 e decrescendo após 150 dias em lactação. A redução no consumo de MS e a adaptação microbiana do rúmen às variações na dieta e a capacidade absortiva podem ter contribuído para as diferenças na uréia no leite em diferentes estádios da lactação (Godden et al., 2001a). Arunvipas et al. (2002) relataram que a concentração de NUL foi baixa no primeiro mês de lactação $(10,14 \mathrm{mg} / \mathrm{dL})$, como conseqüência da redução no CMS, elevou-se ao pico aos 4 meses de lactação $(11,80 \mathrm{mg} / \mathrm{dL})$, após o pico lactacional, em razão do aumento no CMS, e decresceu ao fim da lactação $(10,56 \mathrm{mg} / \mathrm{dL})$, como resultado da variação no CMS e na quantidade de proteína e na relação proteína:energia da dieta. 
Quanto ao número de lactações, os resultados deste estudo corroboram os de Oltner et al. (1985), Canfield et al. (1990) e Godden et al. (2001a), que sugeriram considerar o número de lactações, pois vacas primíparas tiveram menor concentração de NUL que multíparas. Segundo esses autores, esse efeito pode estar relacionado ao fato de que primíparas têm direcionamento pronunciado de nutrientes para crescimento e podem utilizar aminoácidos com maior eficiência.

Jonker et al. (1998) observaram que vacas de primeira lactação apresentaram maiores concentrações estimadas de NUL. Porém, outros autores (Carlsson et al., 1995; Schepers \& Meijer, 1998; Eicher et al., 1999; Arunvipas et al., 2002) não observaram diferenças na concentração de uréia no leite de fêmeas primíparas e multíparas.

As concentrações dos constituintes do leite (gordura, proteína, lactose e sólidos totais) se correlacionaram às de NUL $(\mathrm{P}<0,0001)$. A equação linear ajustou-se bem para NUL e para concentração de gordura $(\mathrm{P}=0,8428)$, proteína ( $\mathrm{P}=0,6684)$ e sólidos totais ( $\mathrm{P}=0,3786)$, não se ajustando, no entanto, para o efeito da lactose $(\mathrm{P}=0,0556)$ (Tabela 3$)$. Pelo coeficiente de determinação, nota-se que, entre os componentes do leite, a concentração de proteína foi o que mais explicou a variabilidade de NUL $\left(r^{2}=0,6000\right)$, seguida pela concentração de sólidos totais $\left(\mathrm{r}^{2}=0,2564\right)$, lactose $\left(r^{2}=0,1967\right)$ e gordura $\left(r^{2}=0,0952\right)$. A cada aumento de uma unidade percentual de proteína, sólidos totais, lactose e gordura do leite, observaram-se decréscimos na concentração de NUL de, aproximadamente, 2,10;0,57; 1,00 e $0,35 \mathrm{mg} / \mathrm{dL}$, respectivamente.
Entretanto, Carlsson \& Perhson (1993) observaram pequena relação entre uréia no leite e concentrações de proteína $(\mathrm{r}=0,03)$ e gordura do leite $(\mathrm{r}=0,06)$ utilizando, respectivamente, 1.709 e 1.724 amostras coletadas em tanque de expansão. Godden et al. (2001a) relataram associação negativa não-linear-porém, numericamente muito pequena - entre uréia no leite e concentrações de gordura e proteína no leite.

Jonker et al. (1999) simularam as concentrações-alvo de NUL e obtiveram média de NUL de $13,1 \mathrm{mg} / \mathrm{dL}$ para uma vaca na segunda lactação com $600 \mathrm{~kg}$ de PV, produzindo $10.000 \mathrm{~kg}$ de leite/lactação, com 3,5\% de gordura e 3,0\% de proteína. Os resultados da simulação comprovaram que, com o aumento ou a diminuição de 0,5 unidade percentual na gordura do leite, a concentração estimada de NUL aumentou ou diminuiu, respectivamente, $1,45 \mathrm{mg} / \mathrm{dL}$. Porém, ao aumentar ou diminuir 0,3 unidade percentual na proteína do leite, a concentração estimada de NUL diminuiu ou aumentou, respectivamente, $1,25 \mathrm{mg} / \mathrm{dL}$, sugerindo que, ao aumentar a proteína do leite, a concentração de NUL diminuiu. Os resultados foram explicados pelo fato de que a maior parte do nitrogênio ingerido é direcionada para a proteína do leite, diminuindo a concentração de NUL.

Arunvipas et al. (2002) relataram que, a cada aumento de 0,1 unidade percentual na proteína do leite, a concentração de NUL diminuiu em $0,2 \mathrm{mg} / \mathrm{dL}$ e também observaram que baixas concentrações de NUL ocorreram em baixas e altas porcentagens de gordura no leite. Porém, outros autores não reportaram associação entre uréia no leite e concentração de gordura e proteína verdadeira (Jaquette et al., 1986;

Tabela 4 - Estimativa dos coeficientes de correlação linear simples entre a produção de leite e as outras variáveis estudadas Table 4 - Coefficient estimates of simple linear correlation analysis between milk yield and other studied variables

\begin{tabular}{|c|c|c|c|c|c|c|}
\hline & \multicolumn{6}{|c|}{ Leite $(M Y)$} \\
\hline & lactkg (lactkg) & STkg (TSkg) & protkg (protkg) & LCG4\% (4\%FCM) & gordkg (gordkg) & prot. (prot.) \\
\hline $\mathrm{r}$ & 0,9649 & 0,9323 & 0,9009 & 0,8436 & 0,6077 & $-0,4232$ \\
\hline \multirow[t]{2}{*}{ Prob. } & 0,0001 & 0,0001 & 0,0001 & 0,0001 & 0,0001 & 0,0001 \\
\hline & $\mathrm{ST}(T S)$ & NUL (MUN) & $\mathrm{NL}(L N)$ & DEL (DIM) & $\operatorname{LCCS}(L S C C)$ & gord. (fat) \\
\hline $\mathrm{r}$ & $-0,3150$ & 0,2670 & 0,2477 & $-0,2465$ & $-0,2096$ & $-0,2072$ \\
\hline \multirow[t]{2}{*}{ Prob. } & 0,0001 & 0,0001 & 0,0001 & 0,0001 & 0,0001 & 0,0001 \\
\hline & peso $(B W)$ & rel. $\mathrm{g} / \mathrm{p}$ (f/p ratio) & lact. (lact.) & & & \\
\hline $\mathrm{r}$ & 0,1421 & $-0,0375$ & 0,0221 & & & \\
\hline Prob. & 0,0001 & 0,0017 & 0,0640 & & & \\
\hline
\end{tabular}

$r$ = coeficiente de correlação; Prob. = probabilidade estatística; leite = produção de leite (kg/dia); lactkg = produção de lactose em kg/dia; STkg = produção de sólidos totais em kg/dia; protkg = produção de proteína em kg/dia; LCG4\% = produção de leite corrigida para $4 \%$ de gordura (kg/dia); gordkg = produção de gordura em kg/dia; prot. = proteína do leite (\%); ST= sólidos totais (\%); NUL= nitrogênio uréico no leite (mg/dL); NL = número de lactações; DEL = dias em lactação; LCCS = In (contagem de células somáticas + 1); gord. = gordura do leite (\%); peso = peso corporal $(\mathrm{kg})$; rel. g/p = relação gordura/proteína; lact. = lactose (\%).

$r=$ coefficient of correlation; Prob. = statistical probability; $M Y=$ milk yield ( $\mathrm{kg} / \mathrm{day}) ; \mathrm{lactkg}=$ lactose yield in $\mathrm{kg} / \mathrm{day} ; \mathrm{TSkg}=$ total solids $y$ ield in $\mathrm{kg} / \mathrm{day} ; \mathrm{protkg}=\mathrm{protein}$ yield in $\mathrm{kg} / \mathrm{day} ; 4 \%$ FCM $=4 \%$ fat corrected milk (kg/day); gordkg = fat yield in kg/day; prot. = milk protein (\%); TS= total solids (\%); $M U N=$ milk urea nitrogen (mg/dL); $L N=$ lactation number; DIM = days in milk; $L S C C=\ln ($ somatic cells count +1$) ;$ fat = milk fat $(\%) ; B W=$ body weight $(\mathrm{kg}) ; \mathrm{f} / \mathrm{p} \mathrm{ratio}=$ fat $/$ protein ratio; lact. = lactose $(\%)$. 
Klusmeyer et al., 1990), o que impede a comparação dos resultados com os deste estudo.

Entre as produções dos componentes do leite, em kg, observa-se na Tabela 3 que a lactose e a proteína foram as variáveis com maiores coeficientes de determinação, respectivamente, 0,6191 e 0,5562, sendo seguidas pela produção de sólidos totais e gordura $\left(\mathrm{r}^{2} \mathrm{de} 0,3680 \mathrm{e} 0,2853\right.$, respectivamente). Verificou-se que, entre essas quatro variáveis, as produções de lactose e proteína $(\mathrm{kg})$ explicam 62 e $56 \%$, respectivamente, da variabilidade total de NUL. As inclinações das retas ("slopes") para essas quatro variáveis foram significativas $(P<0,0001)$. Entretanto, houve falta de ajuste da equação linear para produção de gordura e proteína $(\mathrm{P}<0,01)$, enquanto a equação linear apresentou bom ajuste para produção de lactose $(\mathrm{P}=0,7590)$ e sólidos totais $(\mathrm{P}=0,3238)$, mostrando que a equação linear explica bem o efeito das produções de lactose e sólidos totais sobre as concentrações de NUL. Constatou-se que, a cada aumento na produção de $1 \mathrm{~kg}$ de lactose ou de sólidos totais, houve acréscimo de 1,90 e $0,75 \mathrm{mg} / \mathrm{dL}$ de NUL, respectivamente.

Desse modo, a produção de lactose foi a que mais se correlacionou com NUL e mais explicou a variabilidade total. A produção de lactose foi também altamente correlacionada $(\mathrm{r}=0,9649)$ à produção de leite (Tabela 4).

Pela análise de correlação entre a produção de leite e as outras variáveis estudadas (Tabela 4), verificou-se alta correlação positiva entre as produções de leite e lactose $(\mathrm{r}=0,9649)$ e sólidos totais $(\mathrm{r}=0,9323)$, o que explica a correlação positiva da concentração de NUL com a produção de leite e, conseqüentemente, com a produção de lactose e sólidos totais.

Godden et al. (2001b), considerando dados de rebanho, não encontraram associação entre uréia média no leite e produção de proteína média $(\mathrm{kg})$. Entretanto, a associação foi positiva com a produção de gordura média $(\mathrm{kg})$.

A contagem de células somáticas ( $\mathrm{P}=0,0001)$ influenciou as concentrações de NUL (Tabela 3 ). A equação linear se ajustou bem para explicar os efeitos de LCCS sobre NUL $(\mathrm{P}=0,9000)$, observando-se coeficiente de determinação $\left(\mathrm{r}^{2}\right)$ de 0,1994 . As concentrações de NUL diminuíram em 0,29 $\mathrm{mg} / \mathrm{dL}$ a cada aumento de uma unidade de LCCS. Arunvipas et al. (2002), por sua vez, observaram, a cada aumento de uma unidade no escore linear, redução da concentração de NUL em $0,4 \mathrm{mg} / \mathrm{dL}$.

Wolfschoon-Pombo (1981) relatou que a mastite pode influenciar a concentração de uréia na amostra do quarto infectado da glândula mamária, como resultado da alteração na permeabilidade das membranas das células. Godden et al. (2001a) constataram associação negativa não-linear entre a uréia no leite e o escore linear da contagem de células somáticas, mas relataram que essa associação pode não representar uma relação biológica entre esses dois parâmetros, podendo ser um artefato do instrumento de calibração. Provavelmente, neste estudo, o mesmo não ocorreu, pois a CCS não foi alta.

Meyer et al. (2002) estudaram a relação entre fatores não-nutricionais e NUL e obtiveram um modelo que considera produção de leite, proteína do leite, lactose, CCS, gordura do leite, dias em lactação e número de lactações, gerando um coeficiente de determinação $\left(\mathrm{r}^{2}\right)$ ajustado de 0,1271 . Todavia, esses autores utilizaram regressões múltiplas, pelo método Stepwise, que não permitem a correção do $\mathrm{r}^{2}$, o que explica o valor tão baixo. Neste estudo, foram realizadas regressões lineares, estudando-se os efeitos individuais das variáveis, o que permitiu o ajuste do coeficiente de determinação.

\section{Conclusões}

Entre os fatores não-nutricionais, a produção de leite e a concentração de proteína do leite foram os que mais se correlacionaram com as concentrações de NUL, podendo auxiliar a utilização desse parâmetro como indicador de avaliação nutricional em vacas em lactação.

\section{Agradecimento}

À FAPESP e CNPq, pelo financiamento desta pesquisa. À Fazenda Colorado, pela coleta dos dados.

\section{Literatura Citada}

ARUNVIPAS, P.; DOHOO, I.; VANLEEUWEN, J. et al. The effect of non-nutritional factors on milk urea nitrogen levels in Ayrshire dairy cows. Journal of Dairy Science, v.85, suppl.1, p.320, 2002 .

BRODERICK, G.A.; CLAYTON, M.K. A statistical evaluation of animal and nutritional factors influencing concentration of milk urea nitrogen. Journal of Dairy Science, v.80, p.2964-2971, 1997.

BRUCKENTAL, I.; OLDHAM, J.D.; SUTTON, J.D. Glucose and urea kinetics in early lactation. British Journal of Nutrition, v.44, p.33-45, 1980 .

BUTlER, W.R.; CHERNEY, D.J.R.; ELROD, C.C. Milk urea nitrogen: Field trial results on conception rates and dietary inputs. In: THE CORNELL NUTRITION CONFERENCE FOR FEED MANUFACTURES, 1995, Ithaca. Proceedings... Ithaca: Cornell University Press, 1995. p.89-94.

CANFIELD, R.W.; SNIFFEN, C.J.; BUTLER, W.R. Effects of excess degradable protein on postpartum reproduction and energy balance in dairy cattle. Journal of Dairy Science, v.73, p.2342-2349, 1990.

CARLSSON, J.; BERGSTRÖM, J. The diurnal variation of urea in cow's milk and how milk fat content, storage and preservation affects analysis by a flow injection technique. Acta Veterinaria Scandinavica, v. 35 , p.67-77, 1994 
CARLSSON, J.; PEHRSON, B. The relationships between seasonal variations in the concentration of urea in bulk milk and the production and fertility of dairy herds. Journal of Veterinary Medical Association, v.40, p.205-212, 1993.

CARLSSON, J.; BERGSTRÖM, J.; PEHRSON, B. Variations with breed, age, season, yield, stage of lactation and herd in the concentration of urea in bulk milk and individual cow's milk. Acta Veterinaria Scandinavica, v.36, p.245-254, 1995.

CHALUPA, W. Discussion of protein symposium. Journal of Dairy Science, v.71, p.3470-3481, 1984.

EDWARDS, J.S.; BARTLEY, E.E.; DAYTON, A.D. Effects of dietary protein concentrations on lactating cows. Journal of Dairy Science, v.63, p.243-253, 1980.

EICHER, R.; BOUCHARD, E.; TREMBLAY, A. Cow level sampling factors affecting analysis and interpretation of milk urea concentrations in 2 dairy herds. Canadian Veterinary Journal, v.40, p.487-492, 1999.

EMANUELSON, M.; AHLIN, K.A.; WIKTORSSON, H. Long term feeding of rapeseed meal and full-fat rapeseed of double low cultivars to dairy cows. Livestock Production Science, v.33, p.199-214, 1993.

GODDEN, S.M.; LISSEMORE, K.D.; KELTON, D.F. et al. Factors associated with milk urea concentrations in Ontario dairy cows. Journal of Dairy Science, v.84, p.107-114, 2001 a.

GODDEN, S.M.; LISSEMORE, K.D.; KELTON, D.F. et al. Relationships between milk urea concentrations and nutritional management, production, and economic variables in Ontario dairy herds. Journal of Dairy Science, v. 84, p.1128-1139, 2001b.

GUSTAFSSON, A.H.; CARLSSON, J. Effects of silage quality, protein evaluation systems and milk urea content on milk yield and reproduction in dairy cows. Livestock Production Science, v.37, p.91-105, 1993.

GUSTAFSSON, A.H.; PALMQUIST, D.L. Diurnal variation of rumen ammonia, serum urea, and milk urea in dairy cows at high and low yields. Journal of Dairy Science, v.76, p.475-484, 1993.

HOGAN, J.P. Protein and amino acids nutrition in the high producing cow. Quantitative aspects of nitrogen utilization by ruminants. Journal of Dairy Science, v.58, p.1164$1172,1975$.

JAQUETTE, R.; RAKES, A.H.; CROOM, W.J. Effects of dietary protein on milk, rumen, and blood parameters in dairy cattle fed low fiber diets. Journal of Dairy Science, v.69, p.10261034,1986

JONKER, J.S.; KOHN, R.A.; ERDMAN, R.A. Using milk urea nitrogen to predict nitrogen excretion and utilization efficiency in lactating dairy cows. Journal of Dairy Science, v. 81 , p.2681-2692, 1998.

JONKER, J.S.; KOHN, R.A.; ERDMAN, R.A. Milk urea nitrogen target concentrations for lactating dairy cows fed according to National Research Council recommendations. Journal of Dairy Science, v.82, p.1261-1273, 1999.

KAUFMANN, W. Variation in composition of the raw material with special regard to the urea content. Milchwissenschaft, v.37, p.6-9, 1982 .

KLUSMEYER, T.H.; McCARTHY JR., R.D.; CLARCK, J.H. et al. Effects of source and amount of protein on ruminal fermentation and passage of nutrients to the small intestine of lactating cows. Journal of Dairy Science, v.73, p.3526-3537, 1990.
KOHN, R.A. Caution needed when interpreting MUN. Hoard's Dairyman, v.145, p.58, 2000.

KUNG JR., L.; HUBER, J.T. Performance of high producing cows in early lactation fed protein of various amounts, sources and degradability. Journal of Dairy Science, v.66, p.227-234, 1983 .

MacLEOD, G.K.; GRIEVE, D.G.; McMILLAN, I. et al. Effect of varying protein and energy densities in complete rations. Journal of Dairy Science, v.67, p.1421-1429, 1984.

MEYER, P.M.; MACHADO, P.F.; COLDEBELlA, A. et al. Nonnutritional factors that influence milk urea nitrogen concentration. Journal of Dairy Science, v.85, p.304, 2002 (suppl.1).

NATIONAL RESEARCH COUNCIL - NRC. Nutrient requirements of dairy cattle. 6.ed. Washington, D.C.: National Academy Press, 1989. $157 \mathrm{p}$.

NELSON, A.J. Practical application of MUN analysis. In: ANNUAL NORTH EAST DAIRY PRODUCTION AND MEDICINE SYMPOSIUM, 4., 1995, Syracuse. Proceedings... Syracuse: Cornell University Press, 1995. p.35-45.

NETER, J.; KUTNER, M.H.; NACHTSheiM, C.J. et al. Applied linear regression models. 3.ed. Chicago: Irwin, 1996. 720p.

OLDHAM, J.D. Protein-energy interrelationships in dairy cows. Journal of Dairy Science, v.67, p.1090-1114, 1984.

OLTNER, R.; EMANUELSON, M.; WIKTORSSON, H. Urea concentrations in milk in relation to milk yield, live weight, lactation number and amount and composition of feed given to dairy cows. Livestock Production Science, v.12, p.47-57, 1985.

OLTNER, R.; WIKTORSSON, H. Urea concentrations of milk and blood as influenced by feeding varying amounts of protein and energy to dairy cows. Livestock Production Science, v.10, p.457-467, 1983.

ROSELER, D.K.; FERGUSON, J.D.; SNIFFEN, C.J. et al. Dietary protein degradability effects on plasma and milk urea nitrogen and milk nonprotein nitrogen in Holstein cows. Journal of Dairy Science, v.76, p.525-534, 1993.

STATISTICAL ANALYSES SYSTEM - SAS. SAS/STAT user's guide 8.0. (compact disc). Cary: 1999.

SCHEPERS, A.J.; MEIJER, R.G. Evaluation of the utilization of dietary nitrogen by dairy cows based on urea concentration in milk. Journal of Dairy Science, v.81, p.579-584, 1998.

SOUZA, G.S. Introdução aos modelos de regressão linear e não-linear. Brasília: Embrapa, SPI, Embrapa, SEA, 1998. 489p.

TREVASKIS, L.M.; FULKERSON, W.J. The relationship between various animal and management factors and milk urea, and its association with reproductive performance of dairy cows grazing pasture. Livestock Production Science, v.57, p.255-265, 1999

WOLFSCHOON-POMBO, A.F. Investigations on the amount and composition of NPN in milk. Munich: University of Munich, 1981. 121p. Thesis (PhD) - University of Munich, 1981. 